Will the peer leader please stand up? The personality of the peer leader in elite and non-elite sport teams

Rylander, Pär

University of Gothenburg, Sweden (par.rylander@ped.gu.se)

Heden, Anders

Linnaus University, Sweden (anders.heden@lnu.se)

Archer, Trevor

University of Gothenburg, Sweden (trevor.archer@psy.gu.se)

Garcia, Danilo $\bowtie$

University of Gothenburg, Sweden (danilo.garcia@euromail.se)

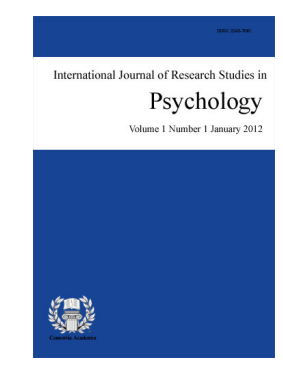

ISSN: 2243-7681 Online ISSN: 2243-769X

OPEN ACCESS

\title{
Abstract
}

We examine associations between self-reported personal characteristics (i.e., skills and Big-Five traits) and peer leadership in team sports at elite and non-elite levels. At a general level, the peer-rated leadership was positively correlated with self-reported athletic skill, positive affect and Openness, while negatively correlated with negative affect and Neuroticism. Moreover, peer leadership was predicted by Extraversion in the non-elite group, while counter-predicted by Agreeableness in the elite group. Suggesting that athletic level might provide a "strong" (elite level) and a "weak" (non-elite level) context in which different traits predict who is perceived as a leader.

Keywords: affectivity; athletic skill; elite athlete; non-elite athlete; peer rated leadership; personality traits 


\section{Will the peer leader please stand up? The personality of the peer leader in elite and non-elite sport teams}

\section{Introduction}

Leadership exerted by members of a group may be as, or even more, effective than that exerted by a formally designated leader. Indeed, the classic "Hawthorne studies" (Sonnenfeld, 1985) implied that group members without a formal leadership vested in them, but seen as leaders by their peers (i.e., peer leaders) often wielded a greater influence on the performance and interrelationships of the work group than did the formal leader (Etzioni, 1974). Peer leadership in groups affects goal-setting and performance (De Souza \& Klein, 1995), group-efficacy (Pescosolido, 2001) and group coherence (Neubert, 1999). Anecdotal evidence from both coaches and athletes attests the importance of both non-peer (i.e., coaches) and peer athletic leaders in team performance (Moran \& Weiss, 2006). Nevertheless, leadership studies have focussed upon peer leadership in experimental laboratory settings neglecting the role of peer leadership in real work groups (Neubert \& Taggar, 2004). Consequentially, in sport research, leadership exerted by the team members (i.e., athletes) has received little attention (Loughead, Hardy, \& Eys, 2006). Most research addresses sport settings focused upon formal leaders as coaches or managers.

Loughead and Hardy (2005), found that coaches exhibited more training and instructions as well as autocratic behaviors than did the athlete peer leaders, who in turn showed more social support, positive feedback and democratic behaviors. Loughead and colleagues (2006) observed that peer leadership was a relatively stable construct throughout a season. Athletes who were perceived as leaders at the beginning of the season were likely to remain leaders at the end of the season. The same study also found that, compared to non-peer leaders, athlete leaders were to a greater extent 'starters' (athletes of the first line-up) and that they had been members of their team on an average of three years. Additionally, athlete peer leaders might fulfil three different leadership functions in their team: task, social and external functions (Eys, Loughead, \& Hardy, 2007). Finally, former team captains (i.e., formal athlete leaders) report that some of their responsibilities as captains included improving the norms, climate and functioning of the team and that dependent on the situation, these formal leaders used both autocratic and democratic behaviors when providing feedback to their team-mates (Dupuis, Bloom, \& Loughead, 2006). These formal leaders also found of great importance, for the teams' performance and functioning, to maintain a good relationship with the coach. In sum, most research focus on the notion that the "leader's main task is to assure all functions that are critical to accomplishing the team's task and to group maintenance" (Graca \& Passos, 2012, p.128; see also Kozlowski et al., 2009; Zaccaro et al., 2001, 2009; Morgeson et al., 2010). Thus, leadership is seen as an input variable. However, according to some researchers (e.g., Graca \& Passos, 2012) teams are surrounded in a context that might influence the team processes and outcomes. Perhaps, even influencing whom peers see as a leader.

In the present study we use the term peer leadership, which focuses upon who and why certain individuals are perceived as leaders (Hogan, Curphy, \& Hogan, 1994). Individuals may be perceived as leaders in "real" teams (Neubert \& Taggar, 2004), through (i) personal characteristics or (ii) performance of valued contribution or fulfilling valued roles for the functioning of the team (e.g., providing social support, interpret events and give advice to other group members on how to carry out tasks, and have a general interest in the well-being of others). Seeing the importance and different functions and behaviors of a peer leader, compared to formal leadership, on team effectiveness; the present study examines which personal characteristics predict who is perceived as leader by teammates in interactive sports.

\subsection{Peer Leadership}

Theories of implicit leadership outline the manner in which personal characteristics may facilitate peer 
Will the peer leader please stand up? The personality of the peer leader in elite and non-elite sport teams

leadership. The "follower perspective" rests on the assumption that an individual is attributed leadership status if others perceive her or him as a leader. Individuals possess cognitive schemas or prototypes of the characteristics of a leader (e.g., decisive, dominant), which are used in assessing and evaluating others; thereby, individuals may be recognized as leaders if they fit leadership prototypes that others have (Lord et al, 1986; Lord \& Emrich, 2001). Much evidence supports the notion that individuals share a set of general beliefs about characteristics linked to leadership (e.g. Smith \& Foti, 1998). Personal characteristics may be classified further into two separate categories; abilities and traits (Ilies, Gerhardt, \& Le, 2004).

Nevertheless, who might be perceived as a leader might be due to the power of the situation (Zimbardo, 2009). Indeed, the notion of "strong" and "weak" situations and the impact of these two types of situation on the relationship between traits and actual behaviour has been discussed by some researchers (e.g., House \& Aditya, 1999; Mischel, 1973). Strong situations are associated with strong behavioral norms, strong incentives for specific types of behaviors, and clear expectations about which behaviors are rewarded or punished under given circumstances with fewer opportunity to express dispositional tendencies. Sports contexts might provide strong and weak situations, with teams developing strong norms and rules of behavior (e.g., "we play to win" in contrast to "we play for fun"). These different contexts might affect the particular traits linked to leadership by elite and non-elite athletes.

\subsection{Personal characteristics and leadership: Abilities and traits}

Ability includes such characteristics as motivation, values, cognitive abilities, intelligence, knowledge, and different types of skills, such as: social skills, problem solving skills, self-monitoring skills (Judge et al, 2002; Zaccaro, 2007). A number of studies have found that individuals who behave in a manner that is highly responsive to social cues and their situational context (i.e., high self-monitoring skills) emerge as leaders to a greater extent than individuals with low self-monitoring skills (e.g., Eby, Cader \& Noble, 2003; Zaccaro, Foti \& Kenny, 1991).

The Big-Five model of personality has stimulated research on the topic of traits and leadership (Judge et al, 2002). The Big-Five model classifies personality traits into five broad dimensions: extraversion, neuroticism, conscientiousness, agreeableness, and openness to experience. Extraversion includes specific traits like active, assertive, energetic, talkative, dominant, and sociable. Neuroticism is the tendency to exhibit negative affect and to show nervousness, tenseness, insecurity, and worry. The conscientiousness dimension includes organization, planning, reliability, and thoroughness. Agreeableness is the tendency to be warm, trusting, gentle, friendly, and forgiving. Openness refers to an experience dimension that includes originality, artistic ability, curiosity, and imagination (Friedman \& Schustack, 2003; John \& Srivastava, 1999).

Generally, findings on characteristics of athlete leaders reveal a dominance of the abilities over the Big-Five traits. Athletic skill appears a salient characteristic, followed by seniority (Glenn \& Horn, 1993; Lee, Coburn \& Partridge, 1983; Loughead, Hardy \& Eys, 2006). Dupuis and colleagues (2006) also found that good communication skills were significant among the team captains in their study. Nevertheless, there is both indirect and direct evidence that personality traits are involved - for example, captains seem to share three personal qualities: remaining positive (extraversion), controlling emotions (low neuroticism), and trusting and respectful (agreeableness) (Dupuis et al., 2006). Among female athletes, competitive trait anxiety (i.e., high in the trait of neuroticism), along skill and perceived competence, predicts peer ratings of leadership behaviors (Glenn \& Horn, 1993; for a replication of these results among both male and female adolescents see Moran \& Weiss, 2006). Moran and Weiss (2006) also confirmed that perceived ability by peers predicted who was referred as a peer leader and that there is a relationship between peer leadership and trait characteristics such as independent (openness), energetic (extraversion), competitive (extraversion), makes decisions easily (openness), never gives up (conscientiousness), self-confident (low neuroticism), stands up well under pressure (neuroticism), emotional, able to devote self completely to others, gentle, helpful of others, kind, understanding of others, aware of feelings of others, and warm in relations with others (all agreeableness). In sum, peer leadership might be 
Rylander, P., Heden, A., Archer, T., \& Garcia, D.

classified under the Big-Five traits taxonomy (Moran \& Weiss, 2006; Glenn \& Horn, 1993). We suggest that the ratings made by peers reflect personality characteristics of leadership prototypes. Table 1 presents a possible categorization of athletic leader characteristics as provided by the Big-Five model.

\section{Table 1}

Categorization of characteristics of the peer leader using the Big-Five taxonomy.

\begin{tabular}{lllll}
\hline \multicolumn{1}{c}{ Extraversion } & \multicolumn{1}{c}{ Neuroticism } & \multicolumn{1}{c}{ Agreeableness } & Conscientiousness & \multicolumn{1}{c}{ Openness } \\
\hline Energetic, & Low & Gentle, & Persistent, & Makes decisions \\
Competitive, & self-confidence, & Able to devote self & Independent, & easily \\
Optimistic, & Low stress level, & completely to & Organized, & \\
Determined, & High competitive & others, & Responsible, & \\
Positive, & trait-anxiety, & Kind, & \\
Confident, & Low ability to & Helpful, & \\
& control emotions, & Warm in relations & \\
& Low internal locus & with others, & \\
& of control & Trusting, & \\
& & Respectful, & \\
& & & \\
& & & \\
& & Ronest, & \\
& & & \\
& &
\end{tabular}

Moreover, neuroticism and extraversion have been linked to negative and positive affectivity, respectively (Heller, Watson \& Ilies, 2004). As stated in the introduction, athlete peer leaders might fulfil three different leadership functions in their team: task, social and external functions (Eys et al., 2007). The relationship between traits and affectivity is important in regard to peer leadership because positive and negative affect might be complementary to extraversion and neuroticism-positive and negative affect are suggested to involve more mood and social traits than extraversion and neuroticism (for a review, see Gunderson, Triebwasser, Phillips, \& Sullivan, 1999). Indeed, positive affect reflects an individual's dispositional tendency to experience positive and pleasant emotions, such as enthusiasm, joy and alertness. Negative affect on the other hand, reflects expressions of unpleasant feelings such as anger, shame, guilt and depressiveness (Watson, Clark \& Tellegen, 1988). Individuals characterized by high negative affect experience anxiety, stress and a low sense of control, while high positive affect individuals shows a greater appreciation of life, feel more secure, are more self-confident (Varg, 1997), and are prone to choose strategies related to agentic (i.e., self-directed behavior) and communal (i.e., cooperation) values when striving after their well-being (Schütz et al., 2013).

\subsection{The present study}

Previous research has provided evidence that personal characteristics contribute to who is seen as the athlete leader-both abilities (e.g., skills, intelligence) and traits have shown to predict peer rated leadership. However, as noted by Hogan and colleagues (1994) most of the studies on peer leadership have used experimental groups without a formal leader and have typically been concerned with whom is "...perceived as leader like when there is only limited information about that person's actual performance" (p. 496). Interactive team sports differ from these experimental groups in three important aspects. Firstly, they do have a formally selected leader and most often more than one. Secondly, feedback on the performance of the athletes is instant and available to all members of the team. Thirdly, interactive team sports exist over longer periods of time.

The present study examines which personal characteristics predict who is perceived as a leader by teammates in interactive team sports. A secondary purpose was to ascertain whether any effect of different sporting levels (i.e., elite level, non-elite level) had an effect on who (i.e., personal characteristics) was perceived as the athlete leader. At a general level we expected skilled athletes to be perceives as leaders by peers. We also expected Big-Five traits to predict peer leadership. Nevertheless, if the athletic level provides a strong (elite level) and a weak (non-elite level) context, then different traits might predict whom peers perceive as a leader. 


\section{Method}

\subsection{Participants}

The participants were 116 athletes (60 female, 56 male), convenience sample, representing eight teams from three interactive team sports - soccer (3 teams), team handball (4 teams), floor-ball ( 1 team). Four of the teams were competing at Swedish elite level (1st or 2nd division) and four at a non-elite level (3rd or lower divisions). The respondents ranged in age from 16 to 34 years, with a mean of 21 years $(S D=3.50)$, and had been members of their current teams for an average 3 years $(S D=2.50)$. Table 2 provides an overview of the gender and athletic level distribution in the study.

\section{Table 2}

Overview of the gender and athletic level distribution in the study.

\begin{tabular}{llll}
\hline & \multicolumn{1}{c}{ Elite } & \multicolumn{1}{c}{ Non-elite } & \multicolumn{1}{c}{ Total } \\
\hline Male & 1 team $(n=17)$ & 3 teams $(n=39)$ & $n=56$ \\
Female & 3 teams $(n=49)$ & 1 team $(n=11)$ & $n=60$ \\
Total & $n=66$ & $n=50$ & $N=116$ \\
\hline
\end{tabular}

\subsection{Measures}

\subsubsection{Peer rated Athlete leadership}

We created a leadership index to assess who is perceived as the athletic peer leader. The index derived from participants' ratings of their teammates on three different statements; "Has a big influence in the team", "Is active in discussions and decisions regarding the team", and "Has the ability to "get people on board". Ratings were made on a 5-point Likert scale ( $1=$ "Not true at all" to $5=$ "completely true"). Thus, all participants obtained a value of athlete leadership, reflecting their athlete leadership status in the team (Cronbach's $\alpha=.96$ ). The index did not include self-ratings, thus, participants rated only their peers.

\subsubsection{Athletic skill}

Athletes' ability was measured by self-ratings on how often the respondents, when not ill or injured, were "starters" in their teams. Responses alternatives were ordered on a five-grade scale $(1=$ Never, $5=$ Always $)$.

\subsubsection{Big five personality traits}

The Big Five Inventory (John, Donahue, and Kentle, 1991) was used to measure the participant personality traits. The Big Five Inventory was developed to meet the needs of a short instrument that still can measure the core features of the Big Five traits: extraversion, agreeableness, conscientiousness, neuroticism and openness to experience. The test consists of 44 items and uses short phrases like "Tends to be lazy" and "Is sometimes rude to others". Cronbach's $\alpha$ for the Big-Five traits ranged from .56 to .67 in this sample. The instrument has been used in Swedish settings in earlier studies (e.g., Kjell et al., 2013).

\subsubsection{Affect}

The Positive Affect Negative Affect Schedule (Watson et al., 1988) was used measure positive and negative affect. The instrument consists of 20 adjectives; ten assessing positive affcet (e.g., "strong", "inspired", "proud) and ten assessing negative affect (e.g., "scared", ashamed", "nervous"). The participants were asked to rate on a five-grade scale to what extent they had felt this way during the last week ( $1=$ "Not at all" and $5=$ "Very much"). The instrument has proven to be both valid and reliable for measuring affective personality (Crawford \& Henry, 2004) and it has been extensively used among Swedes (e.g., Garcia \& Archer, 2012; Garcia, 2013). In the present study Cronbach's $\alpha$ for the positive affect dimension was .85 and for the negative affect dimension .78 . 


\subsection{Procedure}

The coaches of the teams were approached and asked for permission to administer the survey to their athletes. They were also asked to set the time and place when the survey could be conducted. In all cases but one, data was collected at the teams' training facility, either prior or after a practice session. In one case, data was collected following a game at the practice facility. The participants were informed that their participation was voluntary and that their responses would be confidential, but that, due to the nature of the method used their responses would not be anonymous to the researcher. The time for the data collection was immediately before the midpoint of the season for the handball and floor ball teams, and post-season for the soccer teams. This discrepancy was not expected to influence the leadership ratings since athletic peer leadership has shown to be a relatively stable construct throughout a season (Loughead et al., 2006).

\section{Results}

The correlations and inter-correlations between the variables used in the study are presented in Table 3. Athletic leadership showed significant positive correlations to: Age, Years in the team, Athletic skill, PA, and Openness to experience. Conversely, Athletic Leadership was significantly negatively correlated to: NA and Neuroticism.

We performed a Multiple Regression Analysis (MRA) in order to assess the extent to which the independent variables could predict athlete peer leadership. Self-ratings of Athletic Skill, Age, and Extraversion predicted peer ratings of who was perceived as the leader $\left(F(10,99)=6.95, p<.001\right.$, adj. $\left.R^{2}=.34\right)$. In other words, peers perceived older, extrovert, experienced athletes as informal leaders (see Table 4).

\section{Table 3}

Correlation coefficients between Personal Attributes, Athletic Leadership Index, and Personality Traits.

\begin{tabular}{|c|c|c|c|c|c|c|c|c|c|c|c|}
\hline & 1 & 2 & 3 & 4 & 5 & 6 & 7 & 8 & 9 & 10 & 11 \\
\hline (1) Athlete leadership & - & & & & & & & & & & \\
\hline \multicolumn{12}{|l|}{ Personal Attributes } \\
\hline (2) Age & $.44 * *$ & - & & & & & & & & & \\
\hline (3) Years in the team & $.37 * *$ & $.57 * *$ & - & & & & & & & & \\
\hline (4) Athletic skill & $.45^{* *}$ & $.34 * *$ & $.37^{* *}$ & - & & & & & & & \\
\hline \multicolumn{12}{|l|}{ Personal Traits } \\
\hline (5) Positive Affect & $.28 *$ & .10 & .05 & .15 & - & & & & & & \\
\hline (6) Negative Affect & $-.32 * *$ & $-.36 * *$ & $-.30 * *$ & -.18 & -.18 & - & & & & & \\
\hline (7) Extraversion & .12 & -.01 & -.13 & -.02 & $.25^{* *}$ & .10 & - & & & & \\
\hline (8) Neuroticism & $-.22 *$ & $-.29 * *$ & -.08 & .05 & $-.35 * *$ & $.40^{* *}$ & $-.24 *$ & - & & & \\
\hline (9) Agreeableness & .11 & .09 & .13 & .04 & -.04 & .15 & $.40^{* * *}$ & $-.21 *$ & - & & \\
\hline (10) Conscientiousness & .03 & .07 & -.04 & .05 & $.20 *$ & -.07 & $.37 * *$ & $-.33^{* *}$ & $.45^{* *}$ & - & \\
\hline (11) Openness & $.24 *$ & .05 & -.02 & .11 & $.43^{* *}$ & -.05 & .15 & -.09 & -.14 & -.10 & - \\
\hline
\end{tabular}

Note: $* \mathrm{p}<.05 . * * \mathrm{p}<.01$

Two separate MRA were carried out for the two sporting levels (elite and non-elite). For the elite groups (see Table 4), Athletic Skill and Agreeableness predicted Athletic Leadership $\left(F(10,50)=7.65, p<.001\right.$, adj. $R^{2}$ $=.53$ ). It is important to observe that while self-reported athletic skill predicted high peer-ratings of who was seen as a leader, agreeableness predicted low peer-ratings in the Athletic Leadership Index. Thus, the less agreeable and more skilled an athlete rated herself or himself to be, the more she or he was perceived as a leader by peers. In contrast, for the non-elite groups, Athletic Skill and Extraversion predicted peer rated leadership ( $F$ $\left.(10,48)=2.51, p<0.02, a d j . R^{2}=.24\right)$. That is, as for the whole group, skilled extroverts were seen to fit the peers' prototype of an athletic peer leader (see Table 4). These results indicate that more than twice as much of the variance for athlete leadership emergence could be predicted from personal characteristics for elite level 
Will the peer leader please stand up? The personality of the peer leader in elite and non-elite sport teams

athletes than for non-elite level athletes. Moreover, it is plausible to suggest that different traits play significant roles at the different sporting levels.

\section{Discussion}

The present study examined which personal characteristics predict who is perceived as an emergent leader by teammates in interactive team sports. We also aimed to investigate if different personal characteristics predicted who is seen as the peer leader in different sporting levels (i.e., elite level, non-elite level). The results of the present study may be summarised as follows: (i) personal characteristics and peer leadership in interactive team sports emerged as strongly related constructs whereby peer rated leadership was predicted by extraversion in the non-elite group, counter-predicted by agreeableness in the elite group, and by extraversion in the whole population, (ii) Athletic Skill was the strongest predictor of peer rated leadership, and (iii) the perception of peers with regard to who is perceived as a leader was positively correlated to the individual's age, years in the team, Athletic Skill, positive affect, and Openness; but negatively correlated with negative affcet and neuroticism. Nevertheless, Athletic Skill (i.e., ability) was the only characteristic that predicted who was perceived as an athlete leader by peers in the whole sample, the elite sub-sample, and the non-elite sub-sample. Taken together with previous research on athlete leadership (Loughead et al., 2006), where athletic competence or skill has proven to be a salient characteristic of athlete leaders, it appears that team members apply information concerning athletic performance when attributing leadership status.

Data analysis by athletic level (elite, non-elite) confirmed the hypothesis regarding the importance of different traits in different contexts - agreeableness at elite level and extraversion at non-elite level. As stated in the introduction, sports contexts might provide strong and weak situations, with teams developing strong norms and rules of behavior. Thus influencing the linkage between particular traits and peer rated leadership. Higher levels of professionalism create other types of norms and behaviors, due to other forms of incentives, such as money and adoration, whereas participation at non-elite level may rest more on the assumptions of enjoyment and pleasure. It may also be speculated that to be seen as a leader at the elite level entails having to go through a strong process of selection, where only few athletes attain this status. The result of such a process might be that athletes at the elite level share certain similar personal traits. Personal characteristics, both abilities and traits, facilitate peer leadership when they serve as 'identifiable individual characteristics' that differentiate one individual from others of the group (Neubert \& Taggar, 2004).

Table 4

Multiple Regression Analysis with Athletic Leadership Index as the dependent variable and affect, neuroticism, agreeableness, conscientiousness, openness, age, years in team, and Athletic skill as predictor variables in all participants, elite level participants, and non-elite levels participants.

\begin{tabular}{lllll}
\hline Predictor Variable & $\beta$ & Standardized Beta & $\frac{95 \% \text { CI }}{\text { Lower }}$ & Upper \\
\hline All athletes & & & -1.46 & 3.27 \\
Constant & .91 & $.19 *$ & .01 & .62 \\
Age & .31 & $.25^{*}$ & .01 & .12 \\
Athletic skill & .07 & $.31^{* *}$ & .10 & .34 \\
Elite level athletes & .22 & & & 3.90 \\
Constant & -.19 & & -3.47 & -.15 \\
Agreeableness & -.55 & $-.32^{*}$ & -.95 & .34 \\
Athletic skill & .22 & $.34 *$ & .07 & 8.80 \\
Non-elite level Athletes & & & & 1.70 \\
Constant & 4.38 & $.87 * 03$ & .04 \\
Extraversion & .87 & $.36^{*}$ & .03 & .03 \\
Athletic skill & .27 & & &
\end{tabular}




\subsection{Limitations}

In the present study the Big-Five instrument demonstrated low Cronbach's alpha coefficients, which might have distorted the results. Athletic Skill, as conceptualized in this study, reflects the participants' perception of themselves as "being a starter" rather than being a measure of their general skill level. However, the question is if "being an starter" is a good measure of skill or an implicit measure of coach rated leadership. Peers, in turn, might interpret being chosen as a starter by the coach as symbol of leadership. Future studies might need to operationalize Athletic Skill more objectively (e.g., match statistics). Although approximately 34\% of the variance in peer rated leadership was explained by the personal characteristics of the athletes, the majority of the variance, $66 \%$, remained unexplained.

\subsection{Implications and conclusion}

The present study shows that an athlete's ability and personality is partially responsible for she or he being perceived as a leader by peers. Nevertheless, it seems that less agreeable athletes emerges as leaders among elite groups, while more extrovert athletes are the ones perceived as leaders among non-elite groups. It is plausible to suggest that this distinction not only varies between levels but also across situations (Zimbardo, 2009). In other words, a certain type of match might call for a positive and energetic leader (as an extrovert can be expected to behave), while other types of matches might need the emergence of a less gentle, less friendly, and more aggressive leader. Hence, a coach and the team mates must be attuned to the type of situation the team is encountering.

\section{"I suppose leadership at one time meant muscles; but today it means getting along with people” Mahatma Gandhi}

\section{References:}

Crawford, J. R., \& Henry, J. D. (2004). The positive and negative affect schedule (PANAS): Construct validity, measurement properties and normative data in a large non-clinical sample. British Journal of Clinical Psychology, 43(3), 245-265. http://dx.doi.org/10.1348/0144665031752934

De Souza, S. G., \& Klein, H. (1995). Emergent leadership in the group goal-setting process. Small Group Research, 26(4), 475-495. http://dx.doi.org/10.1177/1046496495264002

Dupuis, M., Bloom, G. A., \& Loughead, T. M. (2006). Team captains' perceptions of athlete leadership. Journal of Sport Behavior, 29(2), 60-78.

Eby, L. T., Cader, J., \& Noble, C. L. (2003). Why do high self-monitors emerge as leaders in small groups: A comparative analysis of the behaviors of high versus low self-monitors. Journal of Applied Social Psychology, 33(7), 1457-1479. http://dx.doi.org/10.1111/j.1559-1816.2003.tb01958.x

Etzioni, A. (1972). Modern organizations [in Swedish]. Stockholm: Aldus/Bonniers.

Eys, M. A., Loughead, T. M., \& Hardy, J. (2007). Athlete leadership dispersion and satisfaction in interactive sport teams. Psychology of Sport and Exercise, 8(3), 281-296. http://dx.doi.org/10.1016/j.psychsport.2006.04.005

Friedman, H. S., \&Schustack, M. W. (2003).Personality: Classic theories and modern research. (2:nd edit.). Boston: Allyn and Bacon.

Garcia, D. (2013). La vie en rose: High levels of well-being and events inside and outside autobiographical memory. Journal of Happiness Studies. http://dx.doi.org/10.1007/s10902-013-9443-x

Garcia, D., \& Archer T. (2012). Adolescent life satisfaction and well-being. Journal of Alternative Medicine Research, 4(3), 271-279.

Glenn, S. D., \& Horn, T. S. (1993). Psychological and personal predictors of leadership behavior in female soccer athletes. Journal of Applied Sport Psychology, 5(1), 17-34. http://dx.doi.org/10.1080/10413209308411302

Graca, A. M., \& Passos, A. M. (2012). The role of team leadership in Portuguese child protection teams. 
Will the peer leader please stand up? The personality of the peer leader in elite and non-elite sport teams

Leadership, 8(2), 125-143. http://dx.doi.org/10.1177/1742715011434108

Gunderson, J. G., Triebwasser, J., Phillips, K. A., \& Sullivan, C. N. (1999). Personality and vulnerability to affective disorders. In C. R. Cloninger (Ed.), Personality and psychopathology (pp. 3-32). Washington, DC: American Psychiatric Press.

Heller, D., Watson, D., \& Ilies, R. (2004) The role of person versus situation in life satisfaction: A critical examination. Psychological Bullentine, 130, 574-600. http://dx.doi.org/10.1037/0033-2909.130.4.574

Hogan, R., Curphy, G. J., \& Hogan, J. (1994). What we know about leadership: Effectiveness and personality. American Psychologist, 49(4), 493-504. http://dx.doi.org/10.1037/0003-066X.49.6.493

House, R. J., \& Adity, R. A. (1997). The social scientific study of leadership: Quo vadis?. Journal of Management, 23(3), 409-473. http://dx.doi.org/10.1177/014920639702300306

Ilies, R., Gerhardt, M. W., \& Le, H. (2004). Individual differences in leadership emergence: Integrating meta-analytic findings and behavioral genetics estimates. International Journal of Selection and Assessment, 12(3), 207-218. http://dx.doi.org/10.1111/j.0965-075X.2004.00275.x

John, O. P., Donahue, E. M., \& Kentle, R. L. (1991). The Big Five Inventory--Versions 4a and 54. Berkeley: University of California, Berkeley, Institute of Personality and Social Research.

Judge, T. A., Bono, J. E., Ilies, R., \& Gerhardt, M. W. (2002). Personality and leadership: A qualitative and quantitative review. Journal of Applied Psychology, 87(4), 765-780. http://dx.doi.org/10.1037/0021-9010.87.4.765

Kjell, O. N. E., Nima, A. A., Sikström, S., Archer, T., \& Garcia, D. (2013). The Relationships between Iranian and Swedish Adolescents' Personality Traits, Subjective Well-Being and Psychological Well- Being. PeerJ, 1:e197. http://dx.doi.org/10.7717/peerj.197

Kozlowski, S. W. J., Watola, D. J., Nowakowski, J. M., Kim, B. H., \& Botero, I. C. (2009) Developing adaptative teams: A theory of dynamic team leadership. In: Salas, E., Goodwin, G. F., \& Burke, C. S. (eds) Team Effectiveness in Complex Organizations: Cross-disciplinary Perspectives and Approaches (SIOP Frontiers Series). Mahwah, NJ: LEA.

Lee, M. J., Coburn, T., \& Partridge, R. (1983). The influence of team structure in determining leadership function in association football. Journal of Sport Behavior, 6(2), 59-66.

Lord, R. G., De Vader, C. L., \& Alliger, G. M. (1986). A meta-analysis of the relationship between personality traits and leadership perceptions: An application of validity generalization procedures. Journal of Applied Psychology, 71(3), 402-410. http://dx.doi.org/10.1037/0021-9010.71.3.402

Lord, R. L., \& Emrich, C. G. (2001). Thinking outside the box by looking inside the box: Extending the cognitive revolution in leadership research. Leadership Quarterly, 11(4), 551-579. http://dx.doi.org/10.1016/S1048-9843(00)00060-6

Loughead, T. M., \& Hardy, J. (2005). An examination of coach and peer leader behaviors in sport. Psychology of Sport and Exercise, 6(3), 303-312. http://dx.doi.org/10.1016/j.psychsport.2004.02.001

Loughead, T. M., Hardy, J., \& Eys, M. A. (2006). The nature of athlete leadership. Journal of Sport Behavior, 29(2), 142-158.

Mischel, W. (1973). Toward a social cognitive learning re-conceptualization of personality. Psychological Review, 80(4), 252-283. http://dx.doi.org/10.1037/h0035002

Moran, M. M., \& Weiss, M. R. (2006). Peer leadership in sport: Links with friendship, peer acceptance, psychological characteristics, and athlete ability. Journal of Applied Sport Psychology, 18(2), 97-113. http://dx.doi.org/10.1080/10413200600653501

Morgeson, F. P., DeRue, D. S., \& Karam, E. P. (2010) Leadership in teams: A functional approach to understanding leadership structures and processes. Journal of Management, 36(1), 5-39. http://dx.doi.org/10.1177/0149206309347376

Neubert, M. J. (1999). Too much of a good thing or the more the merrier? Exploring the dispersion and gender composition of informal leadership in manufacturing teams. Small Group Research, 30(5), 635-645. http://dx.doi.org/10.1177/104649649903000507

Neubert, M. J., \& Taggar, S. (2004). Pathways to informal leadership: The moderating role of gender on the relationship of individual differences and team member network centrality to informal leadership 
Rylander, P., Heden, A., Archer, T., \& Garcia, D.

emergence. The Leadership Quarterly, 15(2), 175-194. http://dx.doi.org/10.1016/j.leaqua.2004.02.006

Pescosolido, A., T. (2001). Informal leaders and the development of group efficacy. Small Group Research, 32(1), 74-93. http://dx.doi.org/10.1177/104649640103200104

Smith, J. A., \& Foti, R. J. (1998). A pattern approach to the study of leader emergence. Leadership Quarterly, 9(2), 147-160. http://dx.doi.org/10.1016/S1048-9843(98)90002-9

Sonnenfeld, J. (1985). Shedding Light on the Hawthorne Studies. Journal of Occupational Behavior, 6(2), 111-130. http://dx.doi.org/10.1002/job.4030060203

Schütz, E., Sailer, U., Nima, A., Rosenberg, P., Andersson Arntén, A-C., Archer, T., \& Garcia, D. (2013). The affective profiles in the USA: happiness, depression, life satisfaction, and happiness-increasing strategies. PeerJ, 1:e156. http://dx.doi.org/10.7717/peerj.156

Varg, N. (1997). Negativ affektivitets inverkan på svarsbeteenden i enkätformulär [The influence of negative effect upon responses to questionnaires]. Stockholm: Stockholm University Reports.

Watson, D., Clark, L. A., \& Tellegen, A. (1988). Development and validation of brief measures of positive and negative affect: The PANAS scales. Journal of Personality and Social Psychology, 54(6), 1063-1070. http://dx.doi.org/10.1037/0022-3514.54.6.1063

Zaccaro, S. J. (2007). Trait-based perspectives of leadership. American Psychologist, 62(1), 6-16. http://dx.doi.org/10.1037/0003-066X.62.1.6

Zaccaro, S, J., Foti, R, J., \& Kenny, D, A. (1991). Self-monitoring and trait-based variance in leadership: An investigation of leader flexibility across multiple group situations. Journal of Applied Psychology, 76(2), 308-315. http://dx.doi.org/10.1037/0021-9010.76.2.308

Zaccaro, S. J., Heinen, B., \& Shuffler, M. (2009). Team leadership and team effectiveness. In: Salas, E., Goodwin, G. F., \& Burke, C. S. (eds) Team Effectiveness in Complex Organizations: Cross-disciplinary Perspectives and Approaches (pp. 83-111). New York: Routledge.

Zaccaro, S. J., Rittman, A. L., \& Marks, M. A. (2001). Team leadership. The Leadership Quarterly, 12(4), 451-483. http://dx.doi.org/10.1016/S1048-9843(01)00093-5

Zimbardo, P. (2009). The Lucifer effect - How good people turn evil. London: Rider. 